\title{
Association of Maternal lodine Status With Child IQ: A Meta-Analysis of Individual Participant Data
}

\author{
Deborah Levie, ${ }^{1,2,3,4,5,6}$ Tim I. M. Korevaar, ${ }^{1,2}$ Sarah C. Bath, ${ }^{7}$ Mario Murcia, ${ }^{6,8}$ \\ Mariana Dineva, ${ }^{7}$ Sabrina Llop, ${ }^{6,8}$ Mercedes Espada, 6,9
}

Antonius E. van Herwaarden, ${ }^{\prime}$ Yolanda B. de Rijke, 2,11 Jesús M. Ibarluzea, ${ }^{6,12,13,14}$ Jordi Sunyer, $4,5,6,15$ Henning Tiemeier, ${ }^{3,16}$ Margaret P. Rayman, ${ }^{7}$ Mònica Guxens, $3,4,5,6 *$ and Robin P. Peeters ${ }^{2 *}$

${ }^{1}$ The Generation R Study Group, Erasmus University Medical Centre, 3000 CA Rotterdam, Netherlands; ${ }^{2}$ Department of Internal Medicine, Academic Center For Thyroid Diseases, Erasmus University Medical Centre, 3000 CA Rotterdam, Netherlands; ${ }^{3}$ Department of Child and Adolescent Psychiatry/Psychology, Erasmus University Medical Centre-Sophia Children's Hospital, 3000 CB Rotterdam, Netherlands; ${ }^{4}$ ISGlobal, 08003 Barcelona, Spain; ${ }^{5}$ Pompeu Fabra University, 08003 Barcelona, Spain; ${ }^{6}$ Spanish Consortium for Research on Epidemiology and Public Health, Instituto de Salud Carlos III, 28029 Madrid, Spain; ${ }^{7}$ Department of Nutritional Sciences, Faculty of Health and Medical Sciences, University of Surrey, Guildford GU2 7XH, United Kingdom; ${ }^{8}$ Epidemiology and Environmental Health Joint Research Unit, FISABIOUniversitat Jaume I-Universitat de València, 46020 Valencia, Spain; ${ }^{9}$ Clinical Chemistry Unit, Public Health Laboratory of Bilbao, Basque Government, Parque Tecnológico de Bizkaia, 48160 Derio, Spain; ${ }^{10}$ Department of Laboratory Medicine, Radboud University Nijmegen Medical Centre, 6525 GA Nijmegen, Netherlands; ${ }^{11}$ Department of Clinical Chemistry, Erasmus University Medical Centre, 3015 CN Rotterdam, Netherlands; ${ }^{12}$ Departamento de Sanidad Gobierno Vasco, Subdirección de Salud Pública de Guipúzcoa, 20013 Donostia - San Sebastián, Spain; ${ }^{13}$ BIODONOSTIA Health Research Institute, 20014 Donostia - San Sebastián, Spain; ${ }^{14}$ Faculty of Psychology, University of the Basque Country UPV/EHU, 20018 Donostia - San Sebastián, Spain; ${ }^{15}$ Hospital del Mar Research Institute, 08003 Barcelona, Spain; and ${ }^{16}$ Department of Social and Behavioral Science, Harvard TH Chan School of Public Health, Boston, Massachusetts 02115

ORCiD numbers: 0000-0002-9164-4869 (D. Levie).

Context: Although the consequences of severe iodine deficiency are beyond doubt, the effects of mild to moderate iodine deficiency in pregnancy on child neurodevelopment are less well established.

Objective: To study the association between maternal iodine status during pregnancy and child IQ and identify vulnerable time windows of exposure to suboptimal iodine availability.

Design: Meta-analysis of individual participant data from three prospective population-based birth cohorts: Generation R (Netherlands), INMA (Spain), and ALSPAC (United Kingdom); pregnant women were enrolled between 2002 and 2006, 2003 and 2008, and 1990 and 1992, respectively.

Setting: General community.

Participants: 6180 mother-child pairs with measures of urinary iodine and creatinine concentrations in pregnancy and child IQ. Exclusion criteria were multiple pregnancies, fertility treatment, medication affecting the thyroid, and preexisting thyroid disease.

Main Outcome Measure: Child nonverbal and verbal IQ assessed at 1.5 to 8 years of age.

ISSN Print 0021-972X ISSN Online 1945-7197

Printed in USA

Copyright @ 2019 Endocrine Society

This article has been published under the terms of the Creative Commons Attribution License (CC BY; https://creativecommons.org/licenses/by/4.0/).

Received 27 November 2018. Accepted 22 March 2019

First Published Online 28 March 2019
*M.G. and R.P.P. contributed equally to this study.

Abbreviations: ALSPAC, Avon Longitudinal Study of Parents and Children; FT4, free thyroxine; INMA, INfancia y Medio Ambiente Project; IQR, interquartile range; TPOAb, thyroid peroxidase antibody; UIC, urinary iodine concentration; UI/Creat, urinary iodine/ creatinine ratio. 
Results: There was a positive curvilinear association of urinary iodine/creatinine ratio (UI/Creat) with mean verbal IQ only. UI/Creat $<150 \mu \mathrm{g} / \mathrm{g}$ was not associated with lower nonverbal IQ ( -0.6 point; $95 \% \mathrm{Cl}$ : -1.7 to 0.4 points; $P=0.246)$ or lower verbal IQ $(-0.6$ point; $95 \% \mathrm{Cl}:-1.3$ to 0.1 points; $P=$ 0.082). Stratified analyses showed that the association of UI/Creat with verbal IQ was only present up to 14 weeks of gestation.

Conclusions: Fetal brain development is vulnerable to mild to moderate iodine deficiency, particularly in the first trimester. Our results show that potential randomized controlled trials investigating the effect of iodine supplementation in women with mild to moderate iodine deficiency on child neurodevelopment should begin supplementation not later than the first trimester. (J Clin Endocrinol Metab 104: 5957-5967, 2019)

$l^{\circ}$ odine is an essential trace element required for the production of thyroid hormones; optimal thyroid hormone availability is important for normal fetal brain development $(1,2)$. During pregnancy, there is a higher demand for maternal iodine intake $(3,4)$. This is due to (i) the increased maternal thyroid hormone synthesis required to ensure adequate thyroid hormone availability to the fetus, (ii) greater urinary iodine loss due to an increased glomerular filtration rate, and (iii) placental transfer of iodine to the fetus to facilitate fetal thyroid hormone production. Although severe iodine deficiency is no longer common in Europe, mild to moderate iodine deficiency is still common, especially in pregnant women (5). Severe iodine deficiency in pregnancy results in a higher risk of goiter, hypothyroidism, and mental retardation in the offspring (6). However, the consequences of mild to moderate iodine deficiency in pregnancy on child neurodevelopment are less well established (4).

Mild to moderate iodine deficiency or low iodine intake during pregnancy has been associated with adverse child neurodevelopmental outcomes in some (7-13) but not all studies (14-16). Differences in results between studies may be related to methodological differences (e.g., measurement of iodine status, selected reference group, and available data on confounders), the age at assessment of the neurodevelopmental outcome of interest, the timing of the iodine measurements, and the relative severity of iodine deficiency in the population. Although the main focus in the literature has been on the effects of iodine deficiency, some studies have suggested adverse effects of supplemental intake or excess iodine on either maternal thyroid function $(17,18)$, fetal thyroid function $(19,20)$, or child neurodevelopment $(10,15,16)$.

International health authorities have similar recommendations to ensure optimal iodine status in pregnancy (21-23). It is universally recognized that any necessary iodine supplementation should be commenced before or as early as possible in pregnancy to achieve adequate iodine intake, owing to the susceptibility of the fetal brain to iodine deficiency (23). However, whether the effect of iodine on child cognition varies during different stages of pregnancy is unknown. We therefore assessed the association between maternal iodine status in pregnancy and child IQ across three cohorts of differing iodine status and investigated potential effect modification by gestational age.

\section{Material and Methods}

\section{Study design and populations}

This study was embedded in three cohort studies: Generation R (Netherlands), the INfancia y Medio Ambiente Project (INMA; Spain, three regions), and the Avon Longitudinal Study of Parents and Children (ALSPAC; United Kingdom). The study designs have been described elsewhere (24-27); the ALSPAC study website contains details of all the data that are available through a fully searchable data dictionary and variable search tool (28). For the current study, mother-child pairs were included if a measure of urinary iodine and creatinine concentration during pregnancy and child IQ scores were available. Exclusion criteria were multiple pregnancies, fertility treatment, medication affecting the thyroid, and preexisting thyroid disease. Ethical approval was obtained from the Medical Ethical Committee of the Erasmus Medical Center (Generation R); the Ethical Committee of the Municipal Institute of Medical Investigation and the ethical committees of the hospitals involved in the study (INMA); and the ALSPAC Ethics and Law Committee and local research ethics committees; approval was given by participants and/or parents or guardians of the children by a signed informed consent form.

\section{Maternal iodine status}

Urinary iodine concentration (UIC) and creatinine concentration were measured in spot urine samples stored at $-20^{\circ} \mathrm{C}$ after collection. As part of this study, additional urine samples were analyzed for iodine and creatinine concentrations, and existing measurements from each cohort $(7,19,29)$ were also included. The additional measurements were performed in the same laboratories where the existing measurements were performed. The laboratories were registered with EQUIP and used certified reference materials (Seronorm Urine levels one and two; Nycomed, Norway) for the verification of results. In Generation R, UIC was measured by the Sandell-Kolthoff method. In the INMA, UIC was measured using paired-ion reversed-phase, high-performance liquid chromatography with electrochemical detection at a silver working electrode 
(Waters Chromatography, Milford, MA). In the ALSPAC, UIC was measured on a dynamic reaction cell inductively coupled plasma mass spectrometer. Urinary creatinine concentration was determined by the Jaffe rate method in all cohorts. More information on the measurement methods and the variability between assays can be found in an online repository (30).

In a subset of women, repeated measures of urinary iodine and creatinine were available; we used the earliest available sample as an indicator of iodine status. The urinary iodine/ creatinine ratio (UI/Creat) was used as a measure of iodine status. Because of possible contamination of UIC by the use of iodine-containing test strips in ALSPAC (31), UIC $>500 \mu \mathrm{g} / \mathrm{L}$ and/or UI/Creat $>700 \mu \mathrm{g} / \mathrm{g}$ was excluded from the analyses in this cohort $(\mathrm{N}=363)$. These cutoffs were based on previous work in ALSPAC and from other studies of pregnant women in the United Kingdom $(7,32,33)$. We grouped women's results by UI/Creat as follows: (i) $<150 \mu \mathrm{g} / \mathrm{g}$, (ii) 150 to $<500 \mu \mathrm{g} / \mathrm{g}$, and (iii) $\geq 500 \mu \mathrm{g} / \mathrm{g}$; according to World Health Organization classification, these groups broadly relate to iodine deficiency, sufficiency, and excess, respectively.

\section{Maternal thyroid function}

TSH and free thyroxine (FT4) were measured according to different methodologies between cohorts, which are described in detail elsewhere (34-36). For the analysis, FT4 and TSH concentrations were logarithmically transformed, and cohortspecific SD scores were calculated with a mean of 0 and an SD of 1 based on the data of thyroid peroxidase antibody (TPOAb)-negative women (TPOAb measurements were available in Generation R and ALSPAC). TPOAb titers $\geq 60$ $\mathrm{IU} / \mathrm{mL}$ and $\geq 6 \mathrm{IU} / \mathrm{mL}$ were considered positive in Generation $\mathrm{R}$ and ALSPAC, respectively. These cutoffs were determined by the assay manufacturers.

\section{Nonverbal and verbal IQ scores}

In Generation R, nonverbal IQ was assessed at a median age of 5.9 years using a subset of the Snijders Oomen Nonverbal Intelligence Test (2.5-7-Revised) (37), and verbal IQ was estimated by the short form of the McArthur Communicative Development Inventory (38) at a median age of 1.5 years. In the INMA, nonverbal and verbal IQ scores were assessed at a median age of 4.6 years using the McCarthy Scales of Children's Abilities (39). In the ALSPAC, nonverbal and verbal IQ scores were assessed at a median age of 8.6 years using the Wechsler Intelligence Scale for Children, third UK edition (40). Except for verbal IQ ascertainment in Generation R, which involved a parental questionnaire, all other measurements were performed by psychologists or trained staff. To homogenize the different scores, raw cohort-specific scores were standardized to a mean of 100 and an SD of 15. Children with IQ scores $<50$ or $>150$ $(\mathrm{n}=3)$ were considered outliers and were excluded from the analyses. Suboptimal IQ was defined as an IQ score $<85$.

\section{Potential confounding variables}

Information on maternal age, educational level (low, middle, high), ethnicity/country of birth (cohort-specific categories), parity (zero, one, two or more), prepregnancy body mass index, and smoking during pregnancy (never smoked, smoked in the beginning or until pregnancy confirmed, continued smoking) was collected by questionnaires administered during pregnancy. Gestational age at urine sampling was defined using ultrasonography or last menstrual period. Child sex and age at time of the IQ assessment was obtained during the study visits.

\section{Statistical analyses}

UI/Creat was not normally distributed and was therefore transformed using the natural logarithm; back-transformed values are shown in plots for better interpretation. We studied the associations of UI/Creat with child nonverbal and verbal IQ scores by using one-step and two-step approaches. In the onestep approach, data from the cohorts were pooled, and we performed standard multivariable linear regression models with and without a quadratic term to investigate the possible nonlinear nature of the associations. Nonlinearity was also investigated by using ordinary least squares linear regression models with restricted cubic splines with three knots. With ANOVA, we tested the null hypothesis that child mean IQ was similar across the full range of the natural logarithm of UI/Creat. The decision to use linear regression models instead of multilevel models for the one-step analyses was made because we found no difference between multilevel models with random intercepts and/or slope per cohort vs standard linear regression correcting for cohort (e.g., cohort-specific variable ethnicity/country of birth) when assessed using the Akaike information criterion and log-likelihood tests. In the two-step approach we first studied the associations of UI/Creat $<150 \mu \mathrm{g} / \mathrm{g}$ and UI/Creat $\geq 500 \mu \mathrm{g} / \mathrm{g}$ with child IQ by using linear regression models in each cohort separately. In these analyses, the reference group consisted of women with $\mathrm{UI} / \mathrm{Creat}$ of 150 to $500 \mu \mathrm{g} / \mathrm{g}$. We then combined the cohortspecific effect estimates using random-effects meta-analyses.

Potential effect modification according to gestational age was analyzed by adding a product interaction term between UI/Creat and gestational age to the one-step approach models. Because of the known constraints of statistical power for interaction analyses, a $P$ value $<0.15$ for interaction terms was used to screen for potential relevant modification (41). We further quantified potential relevant differences by performing stratified analyses by tertiles of gestational age ( $\leq 12$ weeks, $>12$ to $\leq 14$ weeks, and $>14$ weeks). We also studied associations with suboptimal IQ (score $<85$ ) by combining cohort-specific estimates from logistic regression models into random-effects meta-analyses.

Sensitivity analyses were designed to study (i) the associations of UI/Creat with verbal IQ score in mother-child pairs from the INMA and ALSPAC only, as verbal IQ was assessed at a preschool age in Generation R; (ii) the association between UI/Creat and maternal TSH and FT4 SD scores within the $\pm 4 \mathrm{SD}$ range around the mean, as TSH and FT4 values outside this range were considered outliers ( $\mathrm{n}=19$ for TSH; $\mathrm{n}=5$ for FT4); and (iii) whether the association between UI/Creat and IQ score could potentially be explained by maternal thyroid function by adjusting for FT4 and TSH in the models.

Heterogeneity between cohorts was assessed using the Cochran Q test and the $\mathrm{I}^{2}$ statistic (42). All models were adjusted for potential confounding variables. However, because of collinearity between maternal ethnicity/country of birth, child age at IQ ascertainment, and cohort, we adjusted for maternal ethnicity/country of birth only in the one-step approach models.

We applied inverse probability weighting to take into account the potential differential loss to follow-up (30) [i.e., to account for selection bias that potentially arises when only the population with available data on iodine status and child IQ is 
included compared with a full initial cohort recruited at pregnancy (43)]. Briefly, we used information available for all participants at recruitment to predict the probability of participation in the study and used the inverse of these probabilities as weights in the analyses so that results would be representative of the initial populations of the cohorts. In addition, missing values in potential confounding variables were imputed using chained equations (44). A total of 25 data sets were generated. A $P$ value $<0.05$ was defined as statistically significant. Statistical analyses were performed with STATA (version 14.0; StataCorp, College Station, TX) and R statistical software (version 3.3.2, package rms).

\section{Results}

The final study population consisted of 6180 motherchild pairs (Fig. 1). The median UIC (UI/Creat) was $159 \mu \mathrm{g} / \mathrm{L}(214 \mu \mathrm{g} / \mathrm{g})$ in Generation R (adequate intake), $128 \mu \mathrm{g} / \mathrm{L}(152 \mu \mathrm{g} / \mathrm{g})$ in the INMA (mild deficiency), and $96 \mu \mathrm{g} / \mathrm{L}(124 \mu \mathrm{g} / \mathrm{g})$ in the ALSPAC (moderate deficiency) (Table 1). Iodine status was determined at a median [interquartile range (IQR)] gestational age of 13.1 (12.1, $14.8)$ weeks, $13.0(12.4,14.1)$ weeks, and $12.0(8.0,16.0)$ weeks in Generation R, the INMA, and the ALSPAC, respectively.

\section{Nonverbal IQ}

Using pooled data in the one-step approach, we observed a positive linear association between the UI/Creat and mean nonverbal IQ score [Fig. 2(a) and (30)], although this association was not statistically significant. Using the two-step approach in which we combined cohortspecific effect estimates using random-effects meta-analysis, neither UI/Creat $<150 \mu \mathrm{g} / \mathrm{g}$ nor UI/Creat $\geq 500 \mu \mathrm{g} / \mathrm{g}$ was associated with nonverbal IQ score $(-0.6$ point; $95 \% \mathrm{CI}$ : -1.7 to 0.4 points; $P=0.246$ and -1.1 points, $95 \% \mathrm{CI}$ : -4.2 to 2.0 points; $P=0.478$ ) [Fig. 2 (b) and 2(c)]. UI/Creat was not associated with suboptimal nonverbal IQ (30).

\section{Verbal IQ}

Using the one-step approach, we observed a positive curvilinear association between UI/Creat and verbal IQ score [Fig. 3(a) and (30)]. There was a positive linear association when measures in preschool children from Generation $\mathrm{R}$ were excluded. Using the two-step approach, neither UI/Creat $<150 \mu \mathrm{g} / \mathrm{g}$ nor UI/Creat $\geq 500 \mu \mathrm{g} / \mathrm{g}$ was associated with verbal IQ score $(-0.6$ point, $95 \% \mathrm{CI}:-1.3$ to 0.1 points; $P=0.082$ and -0.6 point, $95 \% \mathrm{CI}:-2.6$ to 1.4 points; $P=0.552$, respectively) [Fig $3(\mathrm{~b})$ and $3(\mathrm{c})$ or suboptimal verbal IQ score (30)].

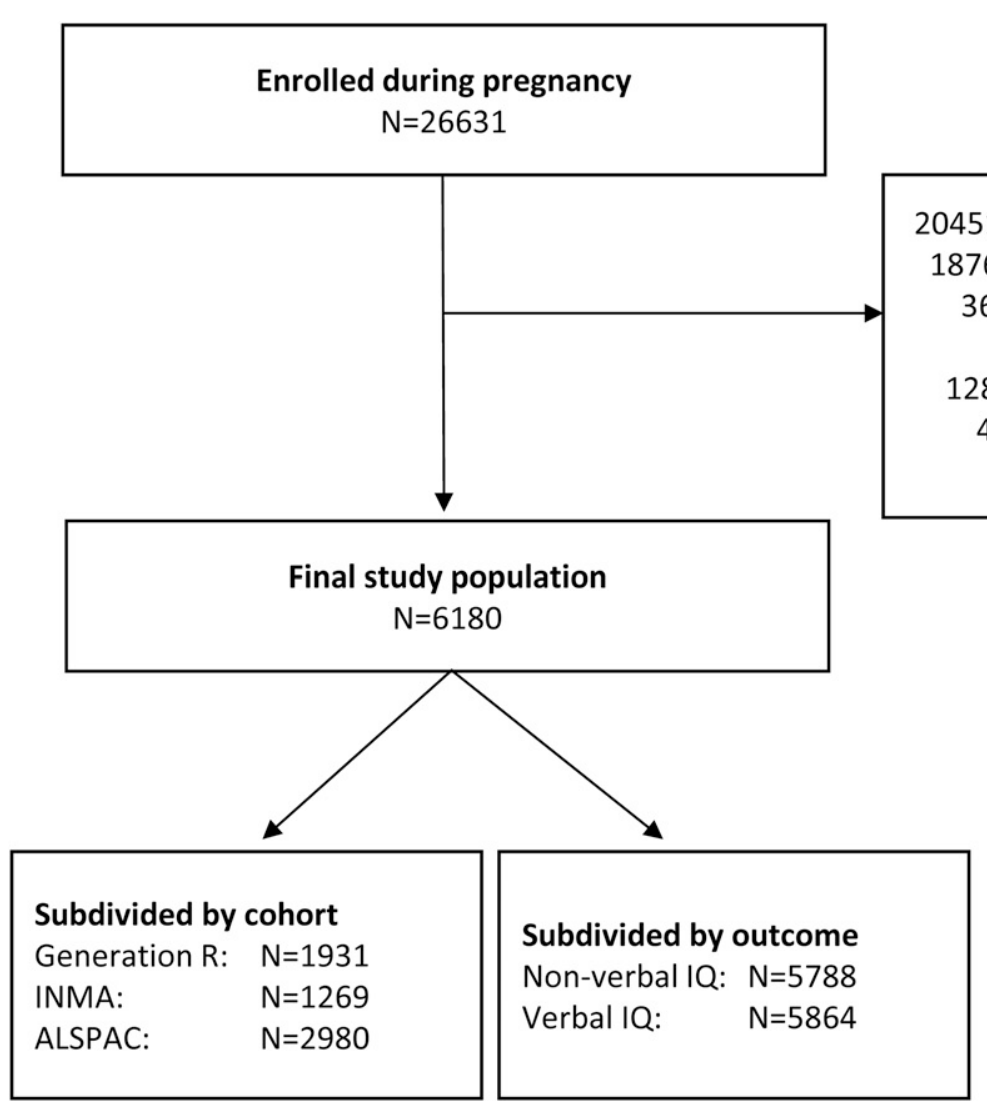

20451 exclusions:

18761 no measures of urinary iodine and creatinine 363 possible contaminated samples in ALSPAC (UIC $>500 \mu \mathrm{g} / \mathrm{L}$ and/or UI/Creat $>700 \mu \mathrm{g} / \mathrm{g}$ 1280 without child IQ data

47 twin pregnancy, thyroid interfering medication usage and/or pre-existing thyroid disease

Figure 1. Flowchart of selection of the study population. 


\section{Table 1. Population Characteristics}

\begin{tabular}{|c|c|c|c|c|c|c|}
\hline & \multicolumn{2}{|c|}{ Generation $R(n=1931)$} & \multicolumn{2}{|c|}{ INMA $(n=1269)$} & \multicolumn{2}{|c|}{ ALSPAC $(n=2980)$} \\
\hline & $\mathbf{n}$ & Values & $\mathbf{n}$ & Values & $\mathbf{n}$ & Values \\
\hline Suboptimal nonverbal $\mathrm{IQ}^{a}$ & 1540 & $175(11.4)$ & 1269 & $216(17.0)$ & 2979 & $479(16.1)$ \\
\hline Suboptimal verbal $1 \mathrm{Q}^{a}$ & 1618 & $279(17.2)$ & 1269 & $211(16.6)$ & 2977 & $480(16.1)$ \\
\hline Female sex, no. (\%) & 1931 & $963(49.9)$ & 1268 & $632(49.8)$ & 2980 & $1514(50.8)$ \\
\hline UI/Creat <150 $\mu \mathrm{g} / \mathrm{g}$, no. (\%) & & $531(27.5)$ & & $623(49.1)$ & & $1831(61.4)$ \\
\hline UI/Creat >500 $\mu \mathrm{g} / \mathrm{g}$, no. (\%) & & $97(5.0)$ & & $52(4.1)$ & & $81(2.7)$ \\
\hline UIC, $\mu \mathrm{g} / \mathrm{L}$, median (IQR) & & $159(90-275)$ & & $128(75-213)$ & & $96(57-153)$ \\
\hline Gestational age at urine sampling, wk & 1931 & & 1267 & & 2980 & \\
\hline Median (IQR) & & $13.1(12.1-14.8)$ & & $13.0(12.4-14.1)$ & & $12.0(8.0-16.0)$ \\
\hline Range (min-max) & & $6.1-30.5$ & & $8.6-39.4$ & & $1.0-42.0$ \\
\hline Gestational age, wk, mean (SD) & 1733 & $13.3(1.9)$ & 1228 & $13.2(1.4)$ & 1118 & $10.3(2.7)$ \\
\hline Educational level, no. (\%) & 1835 & & 1265 & & 2888 & \\
\hline Low & & $154(8.4)$ & & $270(21.3)$ & & $573(19.8)$ \\
\hline Middle & & $760(41.4)$ & & $525(41.5)$ & & $1810(62.7)$ \\
\hline High & & $921(50.2)$ & & $470(37.2)$ & & $505(17.5)$ \\
\hline Maternal ethnicity/country of birth, no. (\%) & 1803 & & 1266 & & 2877 & \\
\hline Spanish & & NA & & $1184(93.5)$ & & NA \\
\hline Latin-American & & NA & & $56(4.4)$ & & NA \\
\hline European/other & & NA & & $26(2.1)$ & & NA \\
\hline Dutch & & $1012(53.2)$ & & NA & & NA \\
\hline Indonesian & & $69(3.6)$ & & NA & & NA \\
\hline Cape Verdean & & $58(3.1)$ & & NA & & NA \\
\hline Parity, no. (\%) & 1931 & & 1267 & & 2877 & \\
\hline 0 & & $1121(58.1)$ & & $727(57.4)$ & & $1346(46.8)$ \\
\hline 1 & & $564(29.2)$ & & $458(36.1)$ & & $992(34.5)$ \\
\hline$\geq 2$ & & $246(12.7)$ & & $82(6.5)$ & & $539(18.7)$ \\
\hline Smoking during pregnancy, no. (\%) & 1744 & & 1254 & & 2926 & \\
\hline Never & & $1319(75.6)$ & & $870(69.4)$ & & $2434(83.2)$ \\
\hline In the beginning of pregnancy & & $168(9.6)$ & & $168(13.4)$ & & $125(4.3)$ \\
\hline Continued & & $257(14.7)$ & & $216(17.2)$ & & $367(12.5)$ \\
\hline Prepregnancy BMI, kg/m², median (IQR) & 1694 & $22.6(20.8-25.2)$ & 1269 & $22.5(20.8-25.0)$ & 2713 & $22.2(20.5-24.4)$ \\
\hline
\end{tabular}

Values are based on unimputed data.

Abbreviations: BMI, body mass index; IQR, interquartile range; NA, not applicable.

${ }^{a}$ Suboptimal is defined as an IQ score $<85$.

\section{Effect modification according to gestational age}

The continuous association of UI/Creat with nonverbal IQ score did not differ according to gestational age at measurement $(P$ for interaction term $=0.306$ ) By contrast, we identified possible effect modification by gestational age in the association with verbal IQ ( $P$ for interaction term $=0.078)$. Stratification by tertile of gestational age showed a positive curvilinear association of UI/Creat with mean child verbal IQ score, with an overall effect of $\sim 5$ IQ points during the first 12 weeks of pregnancy [Fig. 4(a) and (30)]. Furthermore, there was a positive linear association between UI/Creat and mean child verbal IQ score during the 12th to 14th weeks of pregnancy, with an overall effect of $\sim 3$ IQ points [Fig. 4(b)]. This association was no longer present after the 14th week of pregnancy [Fig. 4(c)]. 
(a)

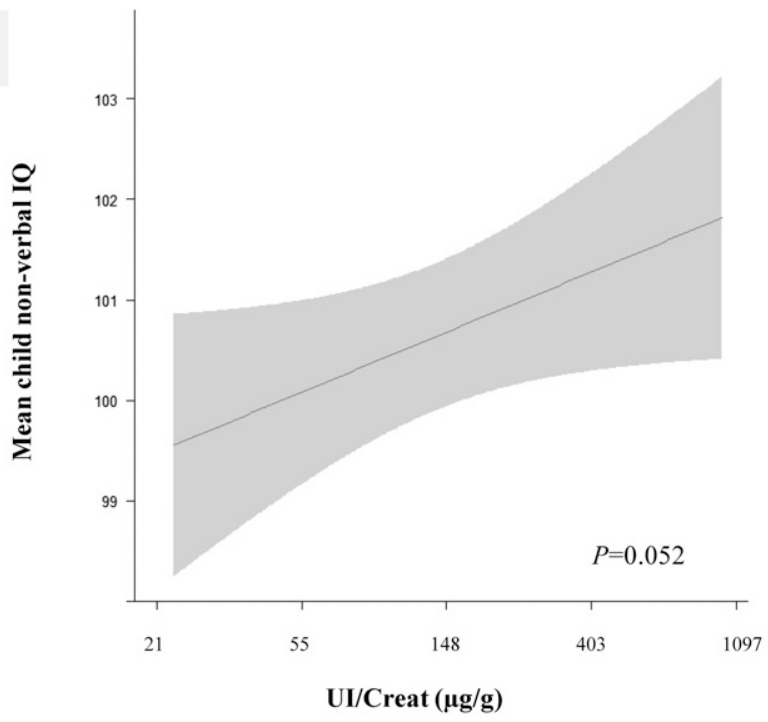

(b)

$\mathrm{UI} /$ Creat $<150 \mu \mathrm{g} / \mathrm{g}$

Cohort

cases/controls

Coef $(95 \% \mathrm{CI})$

Cohort

cases/controls

Coef $(95 \%$ CI)

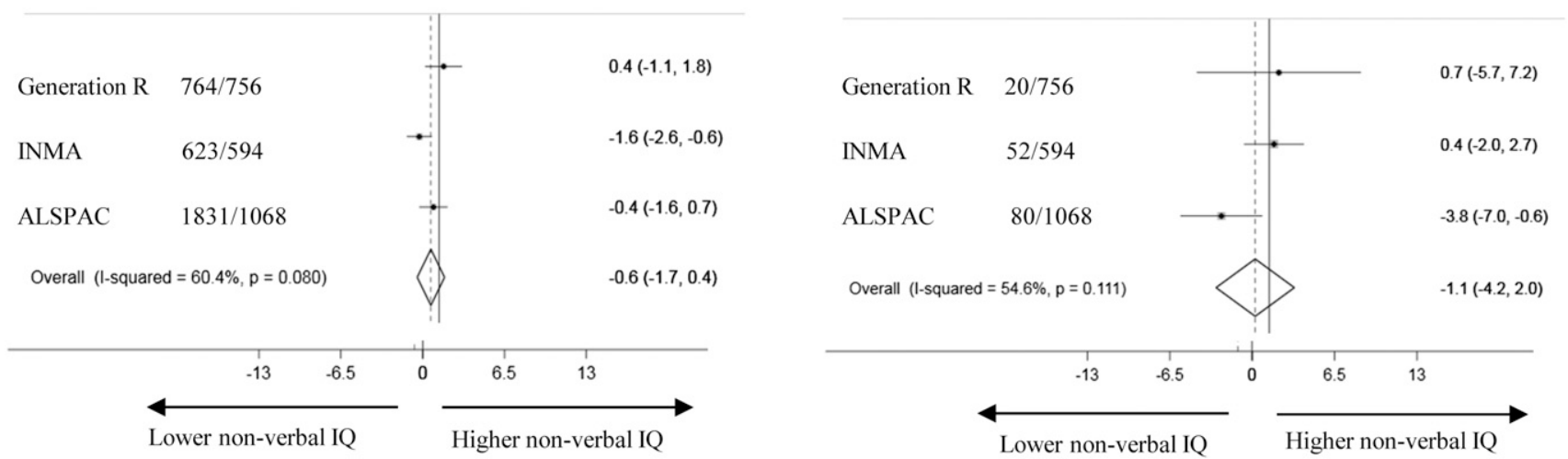

Figure 2. Association of maternal iodine status in pregnancy with child nonverbal IQ score. (a) Continuous association, depicted as the mean child nonverbal IQ score (black line) with $95 \% \mathrm{Cl}$ (gray area) using pooled data. Models were adjusted for gestational age, child sex, maternal ethnicity/country of birth, maternal education, parity, maternal age, prepregnancy body mass index, and smoking during pregnancy. The $P$ value was provided by an ANOVA test of the null hypothesis that mean child nonverbal IQ score was similar across the whole range of the natural logarithm of UI/Creat. (b and c) Forest plots of (b) UI/Creat $<150 \mu \mathrm{g} / \mathrm{g}$ ("deficiency") and (c) UI/Creat $\geq 500 \mu \mathrm{g} / \mathrm{g}$ ("excess") compared with the reference group of UI/Creat $\geq 150$ to $<500 \mu \mathrm{g} / \mathrm{g}$ ("sufficient"), depicted as effect estimate (dot) with $95 \%$ Cl per cohort and overall as estimated by random-effects meta-analysis (diamond). Coef, coefficient.

\section{lodine status and thyroid function}

UI/Creat was not associated with TSH $(0.007,95 \mathrm{CI} \%$ : -0.044 to $0.058 ; P=0.789)$ or with FT4 $(-0.044,95 \mathrm{CI} \%$ : -0.092 to $0.005 ; P=0.079)$. The association did not change between UI/Creat and child nonverbal or verbal IQ score after adjustment for TSH and/or FT4; there was also no sign of effect modification by TSH or FT4 (data not shown). There was no association of UI/Creat with TSH and FT4 in TPOAb-negative women only.

\section{Discussion}

This meta-analysis of individual participant data showed that a lower UI/Creat during pregnancy was associated with lower verbal IQ score. The association of UI/ Creat with verbal IQ score was only seen up to the start of the second trimester (up to the 14th week of gestation). In contrast, we observed no associations between IQ score and UI/Creat $<150 \mu \mathrm{g} / \mathrm{g}$ or $>500 \mu \mathrm{g} / \mathrm{g}$.

Only a few of the previous single-center studies (i.e., the Generation R and ALSPAC cohort studies) focused on child nonverbal IQ score $(7,14)$. They found no association between UI/Creat $<150 \mu \mathrm{g} / \mathrm{g}$ and nonverbal IQ score. It was suggested that iodine deficiency in the Generation $\mathrm{R}$ cohort may not have been severe enough for an association to be identified (14). After combining these two cohorts of contrasting iodine status with a third 
(a)

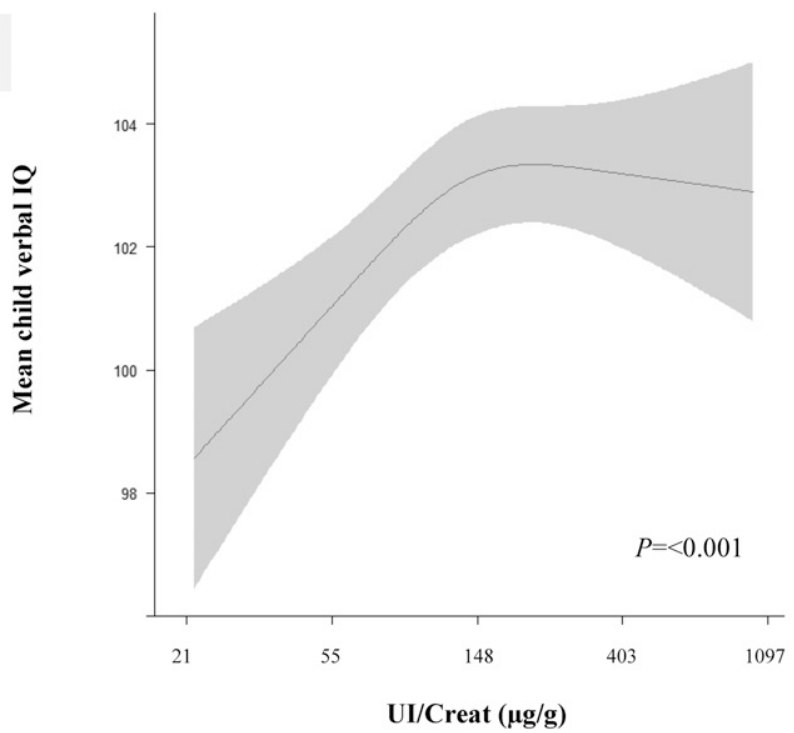

(b)

$\mathrm{UI} / \mathrm{Creat}<150 \mu \mathrm{g} / \mathrm{g}$

Cohort
Coef $(95 \% \mathrm{CI})$

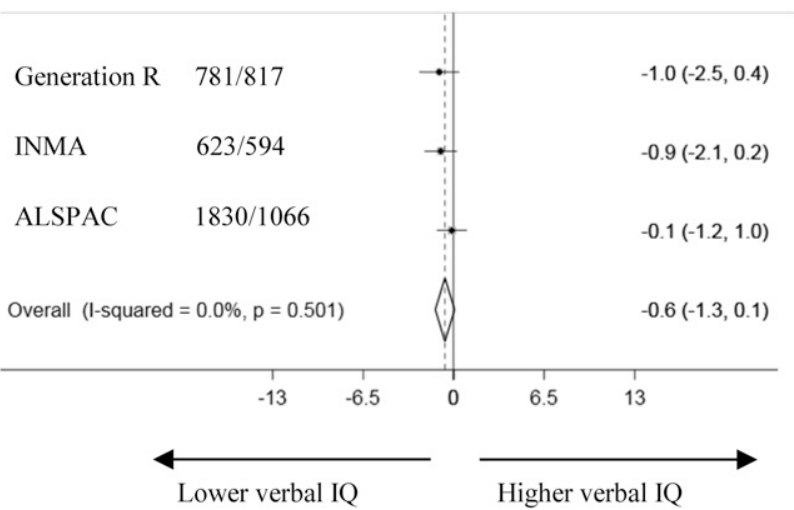

(c)

$\mathrm{UI} / \mathrm{Creat} \geq \mathbf{5 0 0} \mu \mathrm{g} / \mathrm{g}$

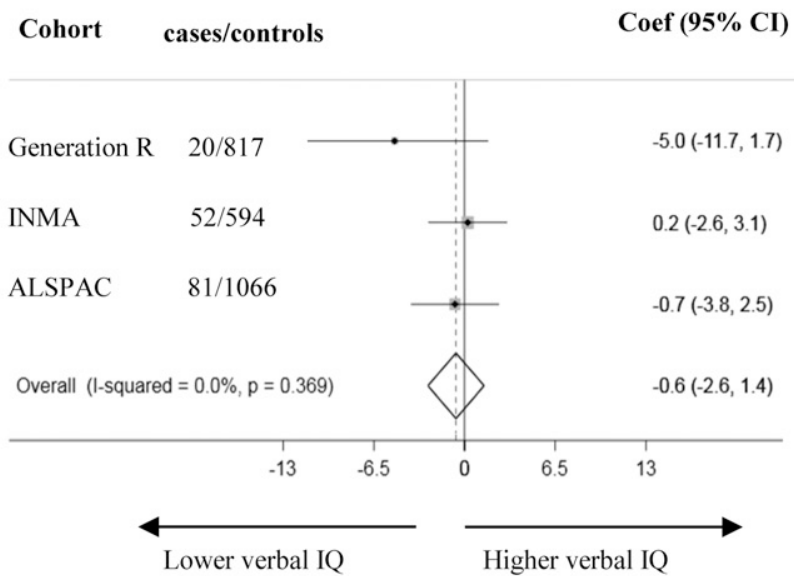

Figure 3. Association of maternal iodine status during pregnancy with child verbal IQ score. (a) Continuous association, depicted as the mean child verbal IQ (black line) with $95 \% \mathrm{CI}$ (gray area) using pooled data. Models were adjusted for gestational age, child sex, maternal ethnicity/ country of birth, maternal education, parity, maternal age, prepregnancy body mass index, and smoking during pregnancy. The $P$ value was provided by an ANOVA test of the null hypothesis that mean child verbal IQ score was similar across the whole range of the natural logarithm of UI/Creat. (b and c) Forest plots of (b) UI/Creat $<150 \mu \mathrm{g} / \mathrm{g}$ ("deficiency") and (c) UI/Creat $\geq 500 \mu \mathrm{g} / \mathrm{g}$ ("excess") compared with the reference group of UI/Creat $\geq 150$ to $<500 \mu \mathrm{g} / \mathrm{g}$ ("sufficient"), depicted as effect estimate (dot) with $95 \% \mathrm{Cl}$ per cohort and overall as estimated by random-effects meta-analysis (diamond). Coef, coefficient.

mildly deficient population (INMA), there was still no effect of iodine deficiency on nonverbal IQ score.

Our meta-analysis using predefined cutoffs showed that UI/Creat $<150 \mu \mathrm{g} / \mathrm{g}$ was not associated with lower verbal IQ score. The estimates we found for the ALSPAC contrasted with the strong negative association of maternal UI/Creat $<150 \mu \mathrm{g} / \mathrm{g}$ in the first trimester (defined as $\leq 13$ weeks' gestation) with child verbal IQ score found in a previously published study from that cohort (fully adjusted: $-2.9,95 \mathrm{CI} \%:-5.0$ to $-0.8 ; P=0.006$ ) (7). However, there are a few important differences between the studies. Compared with the previous publication, the ALSPAC data in our study included a larger number of mother-child pairs (2980 vs 958), fewer iodine-deficient women [1831 $(61.4 \%)$ vs $646(67.4 \%)]$, a study population with a higher UI/Creat [median UI/Creat (IQR): 124 (82 to 199) vs 110 (74 to 170)], and most notably, a higher number of mothers with iodine status measured after the first trimester [1135 (38\%) vs $0(0 \%)$; median gestational age (IQR): 12 ( 8 to 16 ) weeks vs 10.0 (9 to 12 ) weeks]. In addition, we adjusted our analysis for a more stringent selection of variables. Comparison between study populations and additional analysis of the association between UI/Creat $<150 \mu \mathrm{g} / \mathrm{g}$ and a verbal IQ score in the bottom quartile in the whole cohort and in 

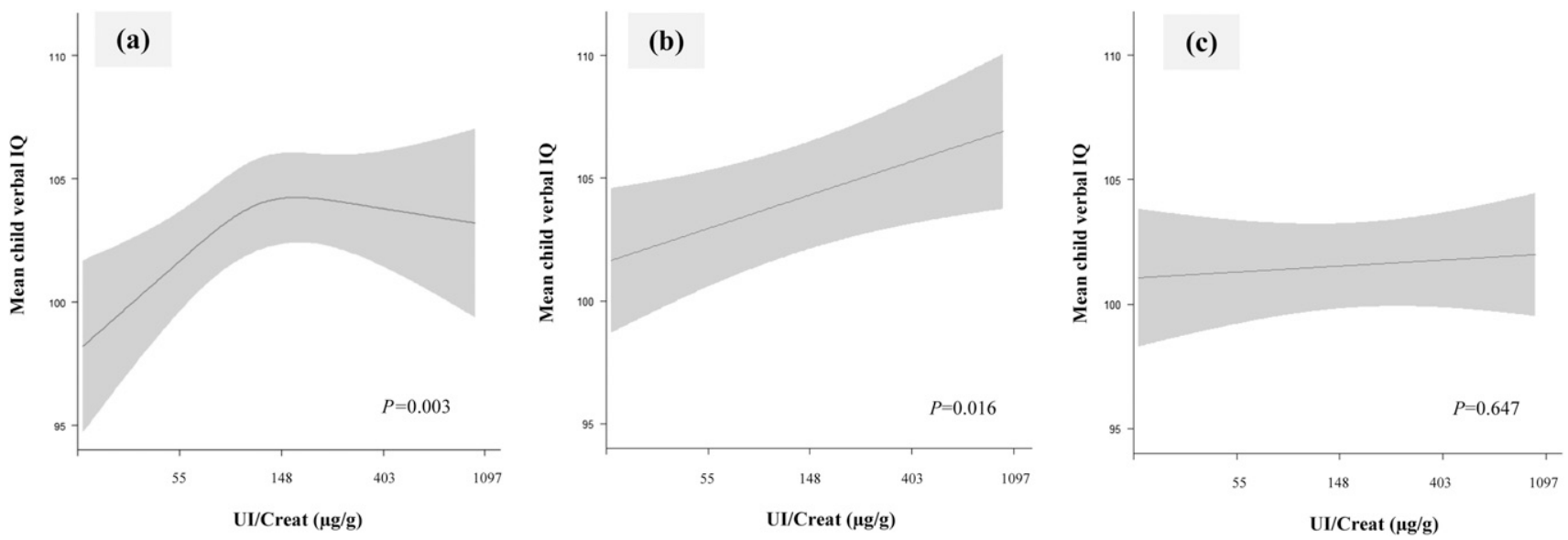

Figure 4. Association of maternal iodine status during pregnancy with child verbal IQ score stratified by tertiles of gestational age. Continuous association, depicted as the mean child verbal IQ (black line) with $95 \% \mathrm{CI}$ (gray area) was restricted to (a) the first 12 weeks of gestation (lowest tertile, median UI/Creat $116 \mu \mathrm{g} / \mathrm{g} ; \mathrm{n}=2209$ ); (b) from weeks 12 to 14 of gestation (middle tertile, median UI/Creat 147 $\mu \mathrm{g} / \mathrm{g} ; \mathrm{n}=1776$ ); and (c) later than week 14 of gestation (highest tertile, median UI/Creat $157 \mu \mathrm{g} / \mathrm{g} ; \mathrm{n}=1879$ ). Models are adjusted for gestational age, child sex, maternal ethnicity/country of birth, maternal education, parity, maternal age, prepregnancy body mass index, and smoking during pregnancy. The $P$ value was provided by an ANOVA test of the null hypothesis that mean child verbal IQ was similar across the whole range of the natural logarithm of UI/Creat.

samples from $\leq 13$ weeks' gestation are described in an online repository (30).

The importance of iodine status in the preconceptional stage for child IQ has recently been shown (45). In early pregnancy, the fetus is fully dependent on the placental transfer of thyroid hormone to support the crucial processes of brain development (2). There is a need for optimal iodine supply from the initiation of conception, implying that sufficient intrathyroidal iodine stores at the preconception stage may well be critical. Indeed, our results suggest that the fetus is particularly sensitive to suboptimal iodine status in the early stages of pregnancy (e.g., $\leq 14$ weeks of gestation) for optimal development of verbal IQ. Effects on verbal IQ could possibly be explained by the impact of mild iodine deficiency, via thyroid hormone, on the auditory system $(13,46)$. In our study, we did not find evidence that the association between UI/Creat and verbal IQ was mediated via maternal thyroid function. Possible explanations could be that urinary iodine excretion is a highly volatile and crude measurement of individual iodine status and/or a crude marker of thyroidal iodine availability. Alternatively, it is also possible that the effects are (in part) mediated via fetal thyroid function.

This study confirms that low iodine status is associated with a reduction in verbal IQ scores, putting these children at potential risk for poorer academic achievement (47). Furthermore, our findings may have implications on a national level (e.g., by negatively affecting economic growth) (48). However, there is still inconclusive evidence that supplementation in pregnant women with mild to moderate iodine deficiency is beneficial for child neurodevelopment $(11,15,16,49-53)$. A recent randomized placebo-controlled trial showed no benefit on children's nonverbal or verbal IQ score with daily supplementation with $200 \mu \mathrm{g}$ of iodine (as potassium iodide) in women with mild iodine deficiency (52). In addition to the already mentioned limitations of that trial (54), our results provide an explanation for the null finding; the trial randomly assigned women at up to 14 weeks of gestation, whereas we showed that maternal iodine status is particularly important in the first trimester. Although our study needs replication, it suggests that the trial might have missed a critical period of vulnerability in women with iodine deficiency. Our results clearly suggest that additional randomized controlled trials should start with iodine supplementation early in the first trimester or preferably even before pregnancy.

The strengths of our study are as follows: A consistent approach to the analysis and harmonization of potential confounding variables across cohorts optimized comparisons; advanced statistical methods were used to overcome selection bias due to loss to follow-up and missing data; and UI/Creat was used as a marker of iodine status. The latter has been shown to be a more valid measure of iodine excretion when used in groups of the same age and sex (55), though we recognize that a single measure may not be reflective of overall iodine status in an individual. A limitation of the study is that the assessment of IQ was performed with different tools at different ages. Nevertheless, the tools measured the same construct (nonverbal or verbal IQ), and the standardization of IQ scores in each cohort facilitated comparison of results across cohorts. Sensitivity analysis in older children only (e.g., excluding children from Generation $\mathrm{R}$, thus reducing 
the age range at which verbal IQ was assessed) confirmed the association between UI/Creat and verbal IQ score. Another limitation is that UIC was measured in different laboratories using different assays; it is known that urinary iodine measurements vary between laboratories (56). We used laboratories that were registered with EQUIP, and the use of certified reference materials enabled us to ensure the accuracy of the results.

In conclusion, this study confirms that iodine status in pregnancy is associated with child IQ scores, and results indicate that the development of verbal IQ of the fetus is particularly vulnerable to suboptimal iodine concentration during early pregnancy up until the start of the second trimester. As such, our results suggest that iodine supplementation after the first 14 weeks of pregnancy could be outside the critical period during which iodine availability affects fetal brain development. However, further studies should replicate these data and investigate the effects of iodine supplementation.

\section{Acknowledgments}

The Generation R study, Netherlands, is conducted by the Erasmus Medical Center in close collaboration with the Faculty of Social Sciences of the Erasmus University Rotterdam, the Municipal Health Service Rotterdam area, Rotterdam, and the Stichting Trombosedienst \& Artsenlaboratorium Rijnmond (STAR-MDC), Rotterdam. The Generation R Study is supported by the Erasmus Medical Center, Rotterdam, the Erasmus University Rotterdam, the Netherlands Organization for Health Research and Development (ZonMw), the Netherlands Organization for Scientific Research (NWO), and the Ministry of Health, Welfare and Sport. A grant from the Sophia Children's Hospital Research Funds supports the neurodevelopmental work on thyroid. R.P.P. is supported by a ZonMw VIDI Grant, project number 1717331.

The INMA study, Spain, was funded by grants from UE (FP7ENV-2011 cod 282957 and HEALTH.2010.2.4.5-1) and Spain: Instituto de Salud Carlos III (Red INMA G03/176; CB06/02/ 0041; FIS-FEDER:PI041436, PI05/1079, PI06/0867, PI081151, FIS-and PS09/00090, PI11/01007, PI11/02591, PI11/02038, PI13/1944, PI13/2032, PI14/00891, PI14/01687, and PI16/1288; Miguel Servet-FEDER CP11/00178, CP15/00025, and CPII16/ 00051, MS13/00054), Generalitat Valenciana: FISABIO (UGP 15-230, UGP-15-244, and UGP-15-249), Generalitat de CatalunyaCIRIT 1999SGR 00241, Fundació La marató de TV3 (090430), Department of Health of the Basque Government (2005111093 and 2009111069), and the Provincial Government of Gipuzkoa (DFG06/004 and DFG08/001).

The ALSPAC study, United Kingdom, is supported by the UK Medical Research Council and Wellcome (Grant ref: 102215/2/ 13/2) and the University of Bristol, which provides core support for the ALSPAC. We are extremely grateful to all the families who took part in this study, the midwives for their help in recruiting them, and the whole ALSPAC team, which includes interviewers, computer and laboratory technicians, clerical workers, research scientists, volunteers, managers, receptionists, and nurses. A comprehensive list of grants funding is available on the ALSPAC website (www.bristol.ac.uk/alspac/external/documents/grantacknowledgements.pdf). The existing iodine measurements in ALSPAC were funded from (i) the NUTRIMENTHE project, which received a research grant from the European Community's 7th Framework Programme (FP7/2008-2013) under grant agreement 212652; and (ii) a PhD studentship that was funded by Wassen International and the Waterloo Foundation (2009 to 2012).

Financial Support: This study was supported in part by the EUthyroid Project: European Union's Horizon 2020 research and innovation programme under grant agreement No. 634453 (to D.L., T.I.M.K., S.C.B., M.D., J.S., M.P.R., M.G., and R.P.P.).

Author Contributions: D.L. did the analyses, interpreted the data, and was involved in writing the manuscript. T.I.M.K., S.C.B., M.D., and M.P.R. contributed to the data analyses, interpretation of the data, and writing of the report. H.T., M.M., M.D., S.L., M.E., J.M.I., and J.S. helped with interpretation of the data and contributed to the writing of the manuscript. A.E.v.H. and Y.B.d.R. helped with the acquisition of data and contributed to the writing of the manuscript. M.G. and R.P.P. supervised the analyses, contributed to the writing of the manuscript, and directed the project.

Correspondence and Reprint Requests: Robin P. Peeters, MD, PhD, Department of Internal Medicine, Academic Center for Thyroid Diseases, Erasmus University Medical Centre, PO Box 2040, 3000 CA Rotterdam, Netherlands. E-mail: r.peeters@erasmusmc.nl.

Disclosure Summary: The authors have nothing to disclose.

\section{References}

1. Lavado-Autric R, Ausó E, García-Velasco JV, Arufe M del C, Escobar del Rey F, Berbel P, Morreale de Escobar G. Early maternal hypothyroxinemia alters histogenesis and cerebral cortex cytoarchitecture of the progeny. J Clin Invest. 2003;111(7):1073-1082.

2. Bernal J. Thyroid hormones and brain development. Vitam Horm. 2005;71:95-122.

3. Trumpff C, De Schepper J, Tafforeau J, Van Oyen H, Vanderfaeillie $\mathrm{J}$, Vandevijvere S. Mild iodine deficiency in pregnancy in Europe and its consequences for cognitive and psychomotor development of children: a review. J Trace Elem Med Biol. 2013;27(3):174-183.

4. Zimmermann MB. Iodine deficiency. Endocr Rev. 2009;30(4): 376-408.

5. Iodine Global Network. Global scorecard of iodine nutrition 2017. Available at: www.ign.org/cm_data/IGN_Global_Map_PW_ 30May2017_1.pdf. Accessed 8 May 2018.

6. Zimmermann MB, Jooste PL, Pandav CS. Iodine-deficiency disorders. Lancet. 2008;372(9645):1251-1262.

7. Bath SC, Steer CD, Golding J, Emmett P, Rayman MP. Effect of inadequate iodine status in UK pregnant women on cognitive outcomes in their children: results from the Avon Longitudinal Study of Parents and Children (ALSPAC). Lancet. 2013; 382(9889):331-337.

8. Hynes KL, Otahal P, Hay I, Burgess JR. Mild iodine deficiency during pregnancy is associated with reduced educational outcomes in the offspring: 9-year follow-up of the gestational iodine cohort. J Clin Endocrinol Metab. 2013;98(5):1954-1962.

9. van Mil NH, Tiemeier H, Bongers-Schokking JJ, Ghassabian A, Hofman A, Hooijkaas H, Jaddoe VWV, de Muinck Keizer-Schrama SM, Steegers EAP, Visser TJ, Visser W, Ross HA, Verhulst FC, de 
Rijke YB, Steegers-Theunissen RPM. Low urinary iodine excretion during early pregnancy is associated with alterations in executive functioning in children. J Nutr. 2012;142(12):2167-2174.

10. Abel MH, Caspersen IH, Meltzer HM, Haugen M, Brandlistuen RE, Aase H, Alexander J, Torheim LE, Brantsæter A-L. Suboptimal maternal iodine intake is associated with impaired child neurodevelopment at 3 years of age in the Norwegian Mother and Child Cohort Study. J Nutr. 2017;147(7):1314-1324.

11. Murcia M, Espada M, Julvez J, Llop S, Lopez-Espinosa M-J, Vioque J, Basterrechea M, Riaño I, González L, Alvarez-Pedrerol M, Tardón A, Ibarluzea J, Rebagliato M. Iodine intake from supplements and diet during pregnancy and child cognitive and motor development: the INMA Mother and Child Cohort Study. J Epidemiol Community Health. 2018;72(3):216-222.

12. Abel MH, Ystrom E, Caspersen IH, Meltzer HM, Aase H, Torheim LE, Askeland RB, Reichborn-Kjennerud T, Brantsæter AL. Maternal iodine intake and offspring attention-deficit/hyperactivity disorder: results from a large prospective cohort study. Nutrients. 2017;9(11):1239.

13. Hynes KL, Otahal P, Burgess JR, Oddy WH, Hay I. Reduced educational outcomes persist into adolescence following mild iodine deficiency in utero, despite adequacy in childhood: 15-year follow-up of the gestational iodine cohort investigating auditory processing speed and working memory. Nutrients. 2017; 9(12):1354.

14. Ghassabian A, Steenweg-de Graaff J, Peeters RP, Ross HA, Jaddoe VW, Hofman A, Verhulst FC, White T, Tiemeier H. Maternal urinary iodine concentration in pregnancy and children's cognition: results from a population-based birth cohort in an iodinesufficient area. BMJ Open. 2014;4(6):e005520.

15. Murcia M, Rebagliato M, Iñiguez C, Lopez-Espinosa M-J, Estarlich M, Plaza B, Barona-Vilar C, Espada M, Vioque J, Ballester F. Effect of iodine supplementation during pregnancy on infant neurodevelopment at 1 year of age. Am J Epidemiol. 2011;173(7):804-812.

16. Rebagliato M, Murcia M, Alvarez-Pedrerol M, Espada M, Fernández-Somoano A, Lertxundi N, Navarrete-Muñoz E-M, Forns J, Aranbarri A, Llop S, Julvez J, Tardón A, Ballester F. Iodine supplementation during pregnancy and infant neuropsychological development: INMA Mother and Child Cohort Study. Am J Epidemiol. 2013;177(9):944-953.

17. Shi X, Han C, Li C, Mao J, Wang W, Xie X, Li C, Xu B, Meng T, Du J, Zhang S, Gao Z, Zhang X, Fan C, Shan Z, Teng W. Optimal and safe upper limits of iodine intake for early pregnancy in iodinesufficient regions: a cross-sectional study of 7190 pregnant women in China. J Clin Endocrinol Metab. 2015;100(4):1630-1638.

18. Sang Z, Wei W, Zhao N, Zhang G, Chen W, Liu H, Shen J, Liu J, Yan Y, Zhang W. Thyroid dysfunction during late gestation is associated with excessive iodine intake in pregnant women. J Clin Endocrinol Metab. 2012;97(8):E1363-E1369.

19. Medici M, Ghassabian A, Visser W, de Muinck Keizer-Schrama SMPF, Jaddoe VWV, Visser WE, Hooijkaas H, Hofman A, Steegers EAP, Bongers-Schokking JJ, Ross HA, Tiemeier H, Visser TJ, de Rijke YB, Peeters RP. Women with high early pregnancy urinary iodine levels have an increased risk of hyperthyroid newborns: the population-based Generation R Study. Clin Endocrinol (Oxf). 2014;80(4):598-606.

20. Connelly KJ, Boston BA, Pearce EN, Sesser D, Snyder D, Braverman LE, Pino S, LaFranchi SH. Congenital hypothyroidism caused by excess prenatal maternal iodine ingestion. J Pediatr. 2012;161(4):760-762.

21. Andersson M, de Benoist B, Delange F, Zupan J; WHO Secretariat. Prevention and control of iodine deficiency in pregnant and lactating women and in children less than 2-years-old: conclusions and recommendations of the Technical Consultation. Public Health Nutr. 2007;10(12A):1606-1611.

22. Alexander EK, Pearce EN, Brent GA, Brown RS, Chen H, Dosiou C, Grobman WA, Laurberg P, Lazarus JH, Mandel SJ, Peeters RP, Sullivan S. 2017 Guidelines of the American Thyroid Association for the diagnosis and management of thyroid disease during pregnancy and the postpartum. Thyroid. 2017;27(3):315-389.

23. Lazarus J, Brown RS, Daumerie C, Hubalewska-Dydejczyk A, Negro R, Vaidya B. 2014 European thyroid association guidelines for the management of subclinical hypothyroidism in pregnancy and in children. Eur Thyroid J. 2014;3(2):76-94.

24. Guxens M, Ballester F, Espada M, Fernández MF, Grimalt JO, Ibarluzea J, Olea N, Rebagliato M, Tardón A, Torrent M, Vioque J, Vrijheid M, Sunyer J; INMA Project. Cohort Profile: the INMA--INfancia y Medio Ambiente--(Environment and Childhood) Project. Int J Epidemiol. 2012;41(4):930-940.

25. Kooijman MN, Kruithof CJ, van Duijn CM, Duijts L, Franco OH, van IJzendoorn MH, de Jongste JC, Klaver CCW, van der Lugt A, Mackenbach JP, Moll HA, Peeters RP, Raat H, Rings EHHM, Rivadeneira F, van der Schroeff MP, Steegers EAP, Tiemeier H, Uitterlinden AG, Verhulst FC, Wolvius E, Felix JF, Jaddoe VWV. The Generation R Study: design and cohort update 2017. Eur J Epidemiol. 2016;31(12):1243-1264.

26. Boyd A, Golding J, Macleod J, Lawlor DA, Fraser A, Henderson J, Molloy L, Ness A, Ring S, Davey Smith G. Cohort Profile: the 'children of the 90s'--the index offspring of the Avon Longitudinal Study of Parents and Children. Int J Epidemiol. 2013;42(1):111-127.

27. Fraser A, Macdonald-Wallis C, Tilling K, Boyd A, Golding J, Davey Smith G, Henderson J, Macleod J, Molloy L, Ness A, Ring S, Nelson SM, Lawlor DA. Cohort Profile: the Avon Longitudinal Study of Parents and Children: ALSPAC mothers cohort. Int J Epidemiol. 2013;42(1):97-110.

28. Executive ALSPAC. Access data and samples. Available at: www.bris.ac.uk/alspac/researchers/data-access/data-dictionary/. Accessed 12 March 2018.

29. Murcia M, Rebagliato M, Espada M, Vioque J, Santa Marina L, Alvarez-Pedrerol M, Lopez-Espinosa M-J, León G, Iñiguez C, Basterrechea M, Guxens M, Lertxundi A, Perales A, Ballester F, Sunyer J; INMA Study Group. Iodine intake in a population of pregnant women: INMA Mother and Child Cohort Study, Spain. J Epidemiol Community Health. 2010;64(12):1094-1099.

30. Levie D, Korevaar TIM, Bath SC, Murcia M, Dineva M, Llop S, Espada M, van Herwaarden AE, de Rijke YB, Ibarluzea JM, Sunyer J, Tiemeier H, Rayman MP, Guxens M, Peeters RP. Data from: Association of maternal iodine status with child IQ: a meta-analysis of individual participant data. RePub Repository 2018. Accessed 27 November 2018. https://repub.eur.nl/pub/112369/.

31. Pearce EN, Lazarus JH, Smyth PP, He X, Smith DF, Pino S, Braverman LE. Urine test strips as a source of iodine contamination. Thyroid. 2009;19(8):919.

32. Pearce EN, Lazarus JH, Smyth PPA, He X, Dall'amico D, Parkes AB, Burns R, Smith DF, Maina A, Bestwick JP, Jooman M, Leung AM, Braverman LE. Perchlorate and thiocyanate exposure and thyroid function in first-trimester pregnant women. J Clin Endocrinol Metab. 2010;95(7):3207-3215.

33. Bath SC, Pop VJM, Furmidge-Owen VL, Broeren MAC, Rayman MP. Thyroglobulin as a functional biomarker of iodine status in a cohort study of pregnant women in the United Kingdom. Thyroid. 2017;27(3):426-433.

34. Korevaar TIM, Muetzel R, Medici M, Chaker L, Jaddoe VWV, de Rijke YB, Steegers EAP, Visser TJ, White T, Tiemeier H, Peeters RP. Association of maternal thyroid function during early pregnancy with offspring IQ and brain morphology in childhood: a populationbased prospective cohort study. Lancet Diabetes Endocrinol. 2016; $4(1): 35-43$.

35. Julvez J, Alvarez-Pedrerol M, Rebagliato M, Murcia M, Forns J, Garcia-Esteban R, Lertxundi N, Espada M, Tardón A, Riaño Galán I, Sunyer J. Thyroxine levels during pregnancy in healthy women and early child neurodevelopment. Epidemiology. 2013; 24(1):150-157.

36. Nelson SM, Haig C, McConnachie A, Sattar N, Ring SM, Smith GD, Lawlor DA, Lindsay RS. Maternal thyroid function and child educational attainment: prospective cohort study. BMJ. 2018;360:k452. 
37. Tellegen PJ, Winkel M, Wijnberg-Williams BJ, Laros JA. SnijdersOomen Nonverbal Intelligence Test. SON-R 21/2-7 Manual and Research Report. Lisse: Swets \& Zeitlinger B.V.; 1998. Available at: www.testresearch.nl/sonr/sonr257manual.pdf. Accessed 25 May 2018.

38. Fenson L, Pethick S, Renda C, Cox JL, Dale PS, Reznick JS. Shortform versions of the MacArthur Communicative Development Inventories. Appl Psycholinguist. 2000;21(1):95-116.

39. McCarthy D. McCarthy Scales of Children's Abilities. New York, NY: Psychological Corporation; 1972.

40. Wechsler D, Golombok S, Rust J. WISC-III UK Wechsler Intelligence Scale for Children. Sidcup, UK: Psychological Corporation; 1992.

41. Selvin S. Statistical Analysis of Epidemiologic Data. New York, NY: Oxford University Press; 1996.

42. Higgins JP, Thompson SG. Quantifying heterogeneity in a metaanalysis. Stat Med. 2002;21(11):1539-1558.

43. Weisskopf MG, Sparrow D, Hu H, Power MC. Biased exposurehealth effect estimates from selection in cohort studies: are environmental studies at particular risk? Environ Health Perspect. 2015;123(11):1113-1122.

44. Sterne JAC, White IR, Carlin JB, Spratt M, Royston P, Kenward MG, Wood AM, Carpenter JR. Multiple imputation for missing data in epidemiological and clinical research: potential and pitfalls. BMJ. 2009;338(jun29 1):b2393.

45. Robinson SM, Crozier SR, Miles EA, Gale CR, Calder PC, Cooper C, Inskip HM, Godfrey KM. Preconception maternal iodine status is positively associated with IQ but not with measures of executive function in childhood. J Nutr. 2018;148(6):959-966.

46. Melse-Boonstra A, Mackenzie I. Iodine deficiency, thyroid function and hearing deficit: a review. Nutr Res Rev. 2013;26(2):110-117.

47. Fergusson DM, Horwood LJ, Ridder EM. Show me the child at seven II: childhood intelligence and later outcomes in adolescence and young adulthood. J Child Psychol Psychiatry. 2005;46(8):850-858.

48. Lynn R, Vanhanen T. National IQs: a review of their educational, cognitive, economic, political, demographic, sociological, epidemiological, geographic and climatic correlates. Intelligence. 2012;40(2):226-234.
49. Berbel P, Mestre JL, Santamaría A, Palazón I, Franco A, Graells M, González-Torga A, de Escobar GM. Delayed neurobehavioral development in children born to pregnant women with mild hypothyroxinemia during the first month of gestation: the importance of early iodine supplementation. Thyroid. 2009;19(5):511-519.

50. Velasco I, Carreira M, Santiago P, Muela JA, García-Fuentes E, Sánchez-Muñoz B, Garriga MJ, González-Fernández MC, Rodríguez A, Caballero FF, Machado A, González-Romero S, Anarte MT, Soriguer F. Effect of iodine prophylaxis during pregnancy on neurocognitive development of children during the first two years of life. J Clin Endocrinol Metab. 2009;94(9):3234-3241.

51. Santiago P, Velasco I, Muela JA, Sánchez B, Martínez J, Rodriguez A, Berrio M, Gutierrez-Repiso C, Carreira M, Moreno A, GarcíaFuentes E, Soriguer F. Infant neurocognitive development is independent of the use of iodised salt or iodine supplements given during pregnancy. Br J Nutr. 2013;110(5):831-839.

52. Gowachirapant S, Jaiswal N, Melse-Boonstra A, Galetti V, Stinca S, Mackenzie I, Thomas S, Thomas T, Winichagoon P, Srinivasan K, Zimmermann MB. Effect of iodine supplementation in pregnant women on child neurodevelopment: a randomised, double-blind, placebo-controlled trial. Lancet Diabetes Endocrinol. 2017; 5(11):853-863.

53. Zhou SJ, Skeaff SA, Ryan P, Doyle LW, Anderson PJ, Kornman L, Mcphee AJ, Yelland LN, Makrides M. The effect of iodine supplementation in pregnancy on early childhood neurodevelopment and clinical outcomes: results of an aborted randomised placebocontrolled trial. Trials. 2015;16(1):563.

54. Bath SC. Iodine supplementation in pregnancy in mildly deficient regions. Lancet Diabetes Endocrinol. 2017;5(11):840-841.

55. Knudsen N, Christiansen E, Brandt-Christensen M, Nygaard B, Perrild H. Age- and sex-adjusted iodine/creatinine ratio: a new standard in epidemiological surveys? Evaluation of three different estimates of iodine excretion based on casual urine samples and comparison to 24 h values. Eur J Clin Nutr. 2000;54(4):361-363.

56. Ittermann T, Johner S, Below H, Leiterer M, Thamm M, Remer T, Völzke H. Interlaboratory variability of urinary iodine measurements. Clin Chem Lab Med. 2018;56(3):441-447. 